\title{
Correlation between coronary atherosclerosis calcification and epicardial adipose tissue volume in patients with nephropathy
}

\author{
HONG ZUO ${ }^{1 *}$, YING ZHANG $^{2 *}$ and QIAOJUAN MA ${ }^{3}$ \\ ${ }^{1}$ Department of Cardiovascular Medicine, Xianyang Central Hospital, Xianyang, Shaanxi 712000; \\ ${ }^{2}$ Department of Nephrology, Hanzhong Central Hospital, Hanzhong, Shaanxi 723000; \\ ${ }^{3}$ Department of Cardiovascular Medicine, The Central Hospital of Tongchuan Mining Bureau, \\ Tongchuan, Shaanxi 727000, P.R. China
}

Received March 19, 2018; Accepted August 31, 2018

DOI: $10.3892 / \mathrm{etm} .2018 .6801$

\begin{abstract}
Correlation between coronary atherosclerosis calcification and epicardial adipose tissue (EAT) volume in patients with nephropathy was investigated. A total of 529 patients with high risk of coronary atherosclerotic nephropathy were selected from August 2013 to September 2016 in Xianyang Central Hospital to serve as research subjects, and their clinical data were retrospectively analyzed. All patients underwent coronary artery and EAT examination using dual-source CT. Correlation between EAT and severity of coronary atherosclerosis, calcification, lesions, and BMI were analyzed. Volume of EAT in patients with atherosclerosis was significantly higher than that in patients without atherosclerosis $(\mathrm{p}<0.05)$. EAT volume was positively correlated with BMI $(r=0.61$, $\mathrm{p}<0.05)$, calcification scores $(\mathrm{r}=0.72, \mathrm{p}<0.05)$ and the number of coronary artery lesions $(\mathrm{r}=0.64, \mathrm{p}<0.05)$ in patients with nephropathy. Coronary atherosclerosis calcification score, number of lesions and BMI are positively correlated with the EAT volume in patients with nephropathy. Detection of EAT volume may serve as a predictor of the occurrence and development of coronary atherosclerosis in the future.
\end{abstract}

\section{Introduction}

The adipose tissue between epicardium and the myocardial surface is called epicardial adipose tissue (EAT) (1). EAT is rich in heart arteries and is one of the most important types of tissues in the human body (2). At present, studies (3-5) have

Correspondence to: Dr Qiaojuan Ma, Department of Cardiovascular Medicine, The Central Hospital of Tongchuan Mining Bureau, 15 Chuankou Road, Tongchuan, Shaanxi 727000, P.R. China E-mail: mqj2110@163.com

*Contributed equally

Key words: coronary atherosclerosis, coronary artery calcification, number of coronary artery lesions, kidney disease, epicardial adipose tissue proven that local inflammatory mediator produced by EAT is closely related to the occurrence and development of coronary atherosclerosis, and its mechanism of action is not yet clear. With the increased incidence of coronary atherosclerosis in recent years (6), the studies on correlations between coronary atherosclerosis and EAT have attracted increased attention. Tsushima et al (7) have shown that measuring the EAT volume can effectively predict coronary artery disease. However, measurement of EAT was not accurate in the past due to the technical difficulties (8). With the rapid development of modern technology, EAT now can be accurately measured by $\mathrm{CT}$. The most serious and common complications of chronic kidney disease are cardiovascular and cerebrovascular diseases (9). Carlsson et al (10) showed that the main causes of death in patients with chronic kidney disease in 2015 were acute coronary syndrome, and heart failure and sudden death after myocardial infarction. However, there is no effective indicator for the detection of sudden cardiovascular disease in patients with chronic kidney disease. Therefore, we speculate that EAT may be used as an indicator of coronary atherosclerosis in patients with renal disease to monitor the occurrence of sudden cardiovascular and cerebrovascular condition. Correlation between EAT and atherosclerosis in patients with nephropathy are not yet clear. Therefore, we analyzed the correlation between EAT and coronary atherosclerosis, calcification, and the number of lesions in patients with nephropathy to evaluate the possible application of EAT as an indicator of atherosclerotic conditions in patients with nephropathy. Our study provided reference for future clinical studies.

\section{Materials and methods}

General information. A retrospective analysis was performed on 529 patients with chronic kidney disease who were highly suspected to have coronary atherosclerosis during preliminary examination in Xianyang Central Hospital (Xianyang, China) from August 2013 to September 2016. Those patients included 354 males and 175 females, and the age ranged from 30 to 60 years, with a mean age of $43.75 \pm 9.62$ years. Inclusion criteria: patients diagnosed with chronic kidney disease in Xianyang Central Hospital; patients aged from 30 to 60 years; patients with complete clinical case, and patients with clinical 
Table I. CT parameter settings.

\begin{tabular}{lc}
\hline Items & Parameters \\
\hline Thickness & $3 \mathrm{~mm}$ \\
A/B tube voltage & $140 \mathrm{kV} / 80 \mathrm{kV}$ \\
Electric current & $350-420 \mathrm{~mA}$ \\
Collimate & $64 \times 0.6 \mathrm{~mm}$ \\
\hline
\end{tabular}

Table II. Differences in EAT volume in patients with or without coronary atherosclerosis $\left(\mathrm{mm}^{3}\right)$.

\begin{tabular}{lcccc}
\hline Variable & $\begin{array}{c}\text { Coronary } \\
\text { atherosclerosis } \\
(\mathrm{n}=319)\end{array}$ & $\begin{array}{c}\text { Non-coronary } \\
\text { atherosclerosis } \\
(\mathrm{n}=210)\end{array}$ & t & P-value \\
\hline EAT volume & $81.42 \pm 29.68$ & $62.15 \pm 36.16$ & 4.23 & $<0.01$ \\
\hline
\end{tabular}

EAT, epicardial adipose tissue.

Table III. Difference in EAT volume in different patients with BMI patients $\left(\mathrm{mm}^{3}\right)$.

\begin{tabular}{lcccc}
\hline Variable & $\begin{array}{c}\text { BMI }<22 \mathrm{~kg} / \mathrm{m}^{2} \\
(\mathrm{n}=221)\end{array}$ & $\begin{array}{c}\mathrm{BMI} \geq 22 \mathrm{~kg} / \mathrm{m}^{2} \\
(\mathrm{n}=308)\end{array}$ & $\mathrm{t}$ & P-value \\
\hline EAR volume & $95.23 \pm 40.53$ & $112.61 \pm 48.17$ & 3.37 & $<0.01$
\end{tabular}

EAT, epicardial adipose tissue.

symptoms of coronary atherosclerosis. Exclusion criteria: patients with cardiovascular and cerebrovascular disease; patients with other respiratory diseases; drug-sensitive patients; pregnant patients; patients with a family history; patients with a history of cancer, and patients with iodine allergy.

The study was approved by the Ethics Committee of Xianyang Central Hospital. The patients signed an informed consent.

Method. CT was performed in strict accordance with operation guideline of 2010 CT examination of the coronary artery (11). Parameter settings are shown in Table I.

Calcification integral scan was performed first, and the heart was scanned from the point $1 \mathrm{~cm}$ below the trachea towards feet. The enhanced scan was preceded by injection of 60-80 ml of umbilical non-ionic iopromide contrast agent with a speed of $5 \mathrm{ml} / \mathrm{sec}$, followed by another 30-40 ml with a speed of $5 \mathrm{ml} / \mathrm{sec}$. Bolus tracking was used to determine scan trigger time, and the optimal diastolic and systolic periods were automatically reconstructed, with a tolerance of $0.75 \mathrm{~mm}$ and overlap of $0.5 \mathrm{~mm}$.

Interpretation of results. The 2015 CT coronary angiography guidelines were used as the diagnostic criteria for atherosclerosis (12). A CT value of $\geq 130 \mathrm{HU}$ and image showing

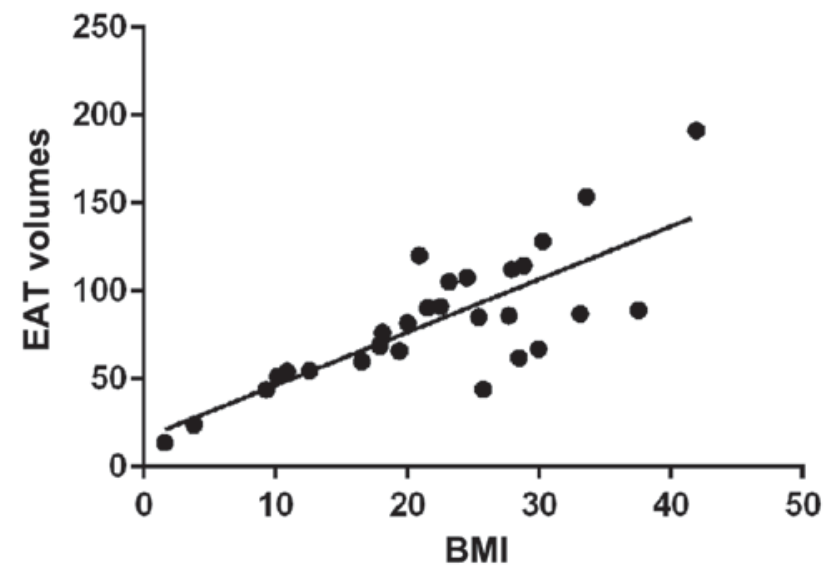

Figure 1. Diagram of linear correlation between BMI and EAT volumes. Mean EAT volume in patients with BMI $<22 \mathrm{~kg} / \mathrm{m}^{2}$ was $95.23 \pm 40.53 \mathrm{~mm}^{3}$, which was significantly higher than that in patients with BMI $\geq 22 \mathrm{~kg} / \mathrm{m}^{2}$ $112.61 \pm 48.17 \mathrm{~mm}^{3}$. Linear correlation analysis showed a positive correlation between EAT volumes and BMI $(r=0.61, p<0.05)$. EAT, epicardial adipose tissue.

a red color was judged as calcification. Imaging results were double-blindly reviewed by three senior imaging physicians in Xianyang Central Hospital. A right coronary artery, left anterior descending, and left circumflex coronary artery lesion was counted as one coronary artery disease, while left main coronary artery 1 lesion was counted as 2 coronary artery lesions. Degree of coronary calcification was divided into $\leq 50$ group, 51-200 group, 201-500 group, 501-1,000 group, and >1,000 group.

Statistical analysis. SPSS 22.0 statistical software (IBM Corp., Armonk, NY, USA) was used to analyze and process data. Measurement data are expressed as mean \pm standard deviation and t-tests were used. Analysis of variance followed by post hoc test (Least Significant Difference) was used for comparisons among multiple groups. Correlation analysis was performed using linear correlation analysis. $\mathrm{P}<0.05$ was considered to be statistically significant.

\section{Results}

EAT volume in patients with different BMI. Mean EAT volume of the 529 patients with nephropathy was $97.81 \pm 49.31 \mathrm{~mm}^{3}$, and the maximum volume was $742 \mathrm{~mm}^{3}$, and the minimum volume was $26.57 \mathrm{~mm}^{3}$. Mean BMI of the 529 patients was $22.37 \pm 9.63 \mathrm{~kg} / \mathrm{m}^{2}$, the highest was $38.74 \mathrm{~kg} / \mathrm{m}^{2}$, and the lowest was $15.23 \mathrm{~kg} / \mathrm{m}^{2}$. Coronary atherosclerosis was seen in 319 out of 529 patients. Mean EAT volume in patients with coronary atherosclerosis was $81.42 \pm 29.68 \mathrm{~mm}^{3}$, and mean EAT volume in patients without coronary atherosclerosis was $62.15 \pm 36.16 \mathrm{~mm}^{3}$, significant differences were found between them $(\mathrm{p}<0.01)$. According to the median BMI, patients were divided into BMI $<22 \mathrm{~kg} / \mathrm{m}^{2}$ group (221 cases) and BMI $>22 \mathrm{~kg} / \mathrm{m}^{2}$ group (308 cases). EAT volume in patients with BMI $<22 \mathrm{~kg} / \mathrm{m}^{2}$ was $95.23 \pm 40.53 \mathrm{~mm}^{3}$, which was significantly higher than that in patients with BMI $\geq 22 \mathrm{~kg} / \mathrm{m}^{2}$ $112.61 \pm 48.17 \mathrm{~mm}^{3}(\mathrm{p}<0.01)$. Linear correlation analysis showed a positive correlation between EAT volume and BMI $(r=0.61$, $\mathrm{p}<0.05$ ) (Tables II and III, Fig. 1). 
Table IV. Different EAT volumes in patients with different calcification scores $\left(\mathrm{mm}^{3}\right)$.

\begin{tabular}{lrc}
\hline Calcification scores & $\mathrm{n}$ & EAT volume \\
\hline$\leq 50$ & 243 & $82.34 \pm 49.78$ \\
$51-200$ & 62 & $91.33 \pm 51.67^{\mathrm{a}}$ \\
$201-500$ & 73 & $102.17 \pm 56.57^{\mathrm{a}, \mathrm{b}}$ \\
$501-1,000$ & 57 & $113.82 \pm 62.02^{\mathrm{a}-\mathrm{c}}$ \\
$>1,000$ & 12 & $104.69 \pm 59.68^{\mathrm{a}-\mathrm{d}}$ \\
F & & 5.24 \\
P-value & & $<0.01$ \\
\hline
\end{tabular}

${ }^{\mathrm{a}} \mathrm{P}<0.05$, compared with $<50$ group; ${ }^{\mathrm{b}} \mathrm{p}<0.05$, compared with $51-200$ group; ${ }^{c} \mathrm{p}<0.05$, compared with $201-500$ group; ${ }^{\mathrm{d}} \mathrm{p}<0.05$, compared with 201-500 group. EAT, epicardial adipose tissue.

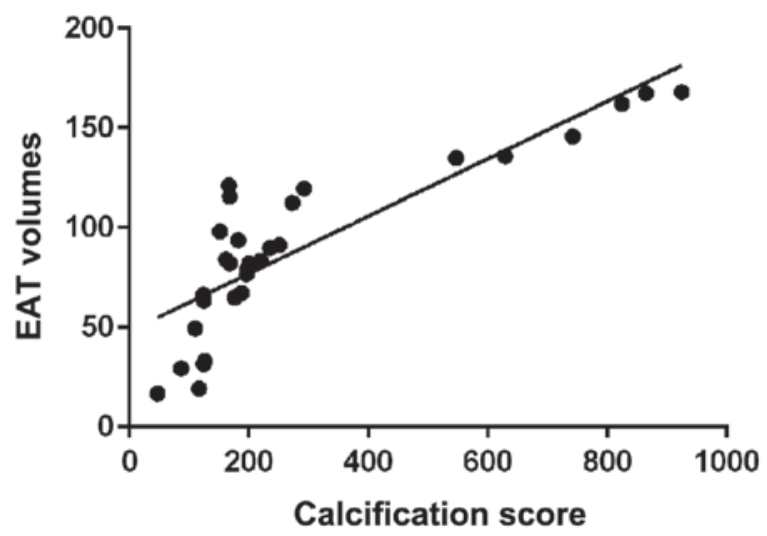

Figure 2. Diagram of linear correlation between calcification score and EAT volumes. Mean EAT volume in patients with calcification integral $\leq 50$ was the smallest, followed by 51-200 group and 201-500 groups, and the volume in 501-1,000 group was the largest, while the EAT volume in $>1,000$ patients was significantly lower than that in 501-1,000 group and significantly higher than that in 201-500 group ( $<<0.05)$. Linear correlation analysis showed a positive correlation between EAT volumes and calcification scores $(\mathrm{r}=0.72$, $\mathrm{p}<0.05)$. EAT, epicardial adipose tissue.

EAT volume in patients with different calcification scores. There were 447 cases of atherosclerosis calcification in 529 patients with nephropathy, of which 243 patients had calcification score $<50$, and mean EAT volume was $82.34 \pm 49.78 \mathrm{~mm}^{3}, 62$ patients had calcification score between 51-200, and mean EAT volume was $91.33 \pm 51.67 \mathrm{~mm}^{3}$, 73 patients had calcification score between 201-500, and mean EAT volume was $113.82 \pm 62.02 \mathrm{~mm}^{3}, 57$ patients had calcification score between 501-1,000, and mean EAT volume was $\left(13.82 \pm 62.02 \mathrm{~mm}^{3}, 57\right.$ patients had calcification score $>1,000$, and mean EAT volume was $104.69 \pm 59.68 \mathrm{~mm}^{3}$. EAT volume in patients with calcification integral $\leq 50$ was the smallest, followed by 51-200 group and 201-500 group, and the volume in 501-1,000 group was the largest. EAT volume of $>1,000$ group was significantly lower than that of the 501-1,000 group and significantly higher than that of 201-500 group $(\mathrm{p}<0.05)$. Linear correlation analysis showed a positive correlation between EAT volume and calcification score $(\mathrm{r}=0.72, \mathrm{p}<0.05)$ (Table IV and Fig. 2).
Table V. EAT volume in patients with different numbers of coronary artery lesions $\left(\mathrm{mm}^{3}\right)$.

\begin{tabular}{lcc}
\hline Groups $(\mathrm{n}=529)$ & $\mathrm{n}$ & EAT volume \\
\hline Non-lesion & 214 & $80.71 \pm 53.27$ \\
1 & 117 & $86.14 \pm 49.37^{\mathrm{a}}$ \\
2 & 94 & $94.84 \pm 52.33^{\mathrm{a}, \mathrm{b}}$ \\
3 & 72 & $101.37 \pm 54.08^{\mathrm{a}-\mathrm{c}}$ \\
4 & 32 & $104.74 \pm 36.68^{\mathrm{a}-\mathrm{d}}$ \\
F & & 3.56 \\
P-value & & $<0.01$ \\
\hline
\end{tabular}

${ }^{\mathrm{a}} \mathrm{P}<0.05$, compared with patients with 1 lesion; ${ }^{\mathrm{b}} \mathrm{p}<0.05$, compared with patients with 2 lesions; ${ }^{c} p<0.05$, compared with patients with 3 lesions; ${ }^{\mathrm{d}} \mathrm{p}<0.05$, compared with patients with 4 lesions. EAT, epicardial adipose tissue.

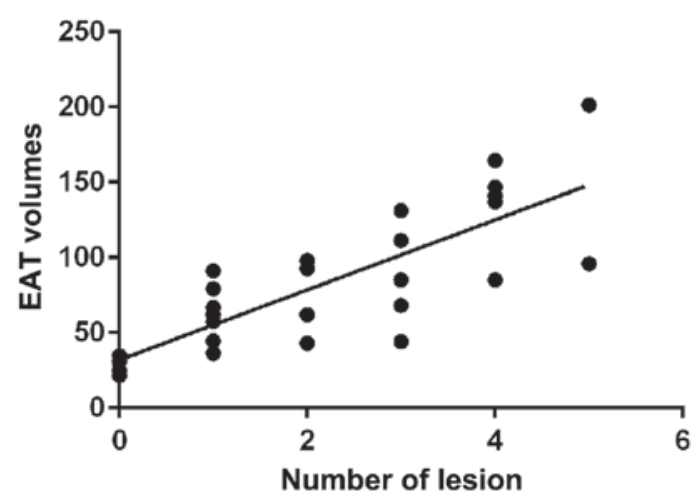

Figure 3. Diagram of linear correlation between numbers of lesions and EAT volumes. EAT volumes increased significantly with the increase in number of lesions. Linear correlation analysis showed that EAT volume was positively correlated with the number of coronary lesions $(r=0.64, p<0.05)$. EAT, epicardial adipose tissue.

EAT volume in patients with different numbers of coronary artery lesions. Coronary lesions were seen in 315 patients with 529 nephropathy, and mean EAT volume in non-lesioned patients was $80.71 \pm 53.27 \mathrm{~mm}^{3}$. There were 117 patients with 1 lesion and the mean EAT volume was $80.71 \pm 53.27 \mathrm{~mm}^{3}$. There were 94 patients with 2 lesions and mean EAT volume was $94.84 \pm 52.33 \mathrm{~mm}^{3}$. There were 72 patients with 3 lesions and mean EAT volume was $101.37 \pm 54.08 \mathrm{~mm}^{3}$. There were 32 patients with 4 lesions and mean EAT volume was $104.74 \pm 36.68 \mathrm{~mm}^{3}$. EAT volume increased with the number of lesions $(p<0.05)$. Linear correlation analysis showed that the EAT volume was positively correlated with the number of coronary lesions $(r=0.64, p<0.05)$ (Table $V$ and Fig. 3).

\section{Discussion}

After the report of the role of EAT in inducing coronary atherosclerosis by local inflammatory mediators, detecting EAT volume has been widely used as a predictor of coronary atherosclerosis. EAT develops from embryonic adipose tissue and shares homology with mesenteric and omental adipose tissue $(13,14)$. Studies have shown that EAT can secrete and 
synthesize a variety of types of cell adipokines and related inflammatory factors to act on the surface of coronary arteries and enhance atherosclerosis $(6,15-17)$. In this study, high-resolution dual-source CT was used to examine the EAT volume in patients with suspected coronary atherosclerosis, which not only provided a better assessment of the coronary artery lesions, but also improved the accuracy of the measurement of the volume of EAT.

Results of this study indicate that the EAT volume is positively correlated with BMI, coronary artery calcification, and the number of coronary artery lesions in patients with nephropathy, which is basically consistent with the findings of Mazurek and Opolski (18) and Pawar et al (19), indicating that EAT volume can be used as an independent indicator to predict the occurrence and development of coronary arteriosclerosis. Higher BMI was accompanied with larger EAT volume. High BMI can increase the level of plasma positive cytokine to promote the process of atherosclerosis (4), but the mechanism of action still needs to be further studied. EAT not only reserves energy, but also serves as an endocrine organ to secrete large amounts of free fatty acids (20). The secreted cytokines affect the metabolism of heart muscle by regulating heart morphology, so as to promote the proliferation of smooth muscle cells of the coronary vascular wall, and accelerate the process of coronary artery stenosis (21). Free fatty acids released by EAT not only induce apoptosis of vascular endothelial cells, but also impair intravascular endothelium relaxation and contraction. Secretion of excessive inflammatory factors such as TNF- $\alpha$ and MCP-1 accelerate the process of coronary atherosclerosis (22). The degree of coronary artery calcification is positively correlated with the severity of lesions and EAT volume. Patients with calcification score $>1,000$ patients had a decreased EAT volume compared with patients with a calcification score of 501-1,000. The reason may be the bias caused by the small number of cases in this study, but the overall correlation between calcification and EAT volume is still positive. Our future studies are expected to confirm the findings. Chaowalit et al (23) showed that there was no significant correlation between calcification and the volume, possibly due to the different detection methods. Chaowalit et al used ultrasound as the main measurement instrument. Ultrasound was only accurate for the measurement of local thickness of EAT. Distribution of EAT thickness on the surface of the heart varies from individual to individual. Ultrasound may not be an appropriate imaging method for measurement of EAT.

In this study, CT was used to detect EAT volume in patients with suspected coronary atherosclerotic nephropathy, and correlations of EAT with BMI, calcification, and pathological conditions were analyzed. There are still deficiencies, such as the small sample size. Our future studies will solve these problems.

In summary, coronary atherosclerosis, BMI, calcification, and number of lesions are positively correlated with the volume of EAT in patients with nephropathy. Detection of EAT volume may serve as an indicator of the occurrence and development of coronary atherosclerosis in the future.

\section{Acknowledgements}

Not applicable.

\section{Funding}

No funding was received.

\section{Availability of data and materials}

The datasets used and/or analyzed during the present study are available from the corresponding author on reasonable request.

\section{Authors' contributions}

$\mathrm{HZ}$ and $\mathrm{YZ}$ drafted the manuscript. HZ and QM analyzed and interpreted calcification integral scan. YZ and QM treated patients and were responsible for statistical analysis. All authors read and approved the final manuscript.

\section{Ethics approval and consent to participate}

The study was approved by the Ethics Committee of Xianyang Central Hospital (Xianyang, China). Signed informed consents were obtained from the patients or guardians.

\section{Patient consent for publication}

Not applicable.

\section{Competing interests}

The authors declare that they have no competing interests.

\section{References}

1. Iacobellis G: Local and systemic effects of the multifaceted epicardial adipose tissue depot. Nat Rev Endocrinol 11: 363-371, 2015.

2. Yamaguchi Y, Cavallero S, Patterson M, Shen H, Xu J, Kumar SR and Sucov HM: Adipogenesis and epicardial adipose tissue: A novel fate of the epicardium induced by mesenchymal transformation and PPAR $\gamma$ activation. Proc Natl Acad Sci USA 112: 2070-2075, 2015

3. Kitagawa T, Yamamoto H, Sentani K, Takahashi S, Tsushima H, Senoo A, Yasui W, Sueda T and Kihara Y: The relationship between inflammation and neoangiogenesis of epicardial adipose tissue and coronary atherosclerosis based on computed tomography analysis. Atherosclerosis 243: 293-299, 2015.

4. Gaborit B, Venteclef N, Ancel P, Pelloux V, Gariboldi V, Leprince P, Amour J, Hatem SN, Jouve E, Dutour A, et al: Human epicardial adipose tissue has a specific transcriptomic signature depending on its anatomical peri-atrial, peri-ventricular, or peri-coronary location. Cardiovasc Res 108: 62-73, 2015.

5. Vacca M, Di Eusanio M, Cariello M, Graziano G, D'Amore S, Petridis FD, D'orazio A, Salvatore L, Tamburro A, Folesani $\mathrm{G}$, et al: Integrative miRNA and whole-genome analyses of epicardial adipose tissue in patients with coronary atherosclerosis. Cardiovasc Res 109: 228-239, 2016.

6. McAninch EA, Fonseca TL, Poggioli R, Panos AL, Salerno TA, Deng Y, Li Y, Bianco AC and Iacobellis G: Epicardial adipose tissue has a unique transcriptome modified in severe coronary artery disease. Obesity (Silver Spring) 23: 1267-1278, 2015.

7. Tsushima H, Yamamoto H, Kitagawa T, Urabe Y, Tatsugami F, Awai $\mathrm{K}$ and Kihara Y: Association of epicardial and abdominal visceral adipose tissue with coronary atherosclerosis in patients with a coronary artery calcium score of zero. Circ J 79: 1084-1091, 2015.

8. Du Y, Ji Q, Cai L, Huang F, Lai Y, Liu Y, Yu J, Han B, Zhu E, Zhang J, et al: Association between omentin-1 expression in human epicardial adipose tissue and coronary atherosclerosis. Cardiovasc Diabetol 15: 90, 2016. 
9. Shah AD, Langenberg C, Rapsomaniki E, Denaxas S, Pujades-Rodriguez M, Gale CP, Deanfield J, Smeeth L, Timmis A and Hemingway H: Type 2 diabetes and incidence of cardiovascular diseases: A cohort study in 1.9 million people. Lancet Diabetes Endocrinol 3: 105-113, 2015.

10. Carlsson AC, Östgren CJ, Nystrom FH, Länne T, Jennersjö P, Larsson A and Ärnlöv J: Association of soluble tumor necrosis factor receptors 1 and 2 with nephropathy, cardiovascular events, and total mortality in type 2 diabetes. Cardiovasc Diabetol 15: 40, 2016.

11. Alexopoulos N, McLean DS, Janik M, Arepalli CD, Stillman AE and Raggi P: Epicardial adipose tissue and coronary artery plaque characteristics. Atherosclerosis 210: 150-154, 2010.

12. SCOT-HEART investigators: CT coronary angiography in patients with suspected angina due to coronary heart disease (SCOT-HEART): An open-label, parallel-group, multicentre trial. Lancet 385: 2383-2391, 2015.

13. Hatem SN, Redheuil A and Gandjbakhch E: Cardiac adipose tissue and atrial fibrillation: The perils of adiposity. Cardiovasc Res 109: 502-509, 2016.

14. Ohyama K, Matsumoto Y, Nishimiya K, Hao K, Tsuburaya R Ota H, Amamizu H, Uzuka H, Takahashi J, Ito K, et al: Increased coronary perivascular adipose tissue volume in patients with vasospastic angina. Circ J 80: 1653-1656, 2016.

15. Torres T, Bettencourt N, Mendonça D, Vasconcelos C, Gama V, Silva BM and Selores M: Epicardial adipose tissue and coronary artery calcification in psoriasis patients. J Eur Acad Dermatol Venereol 29: 270-277, 2015.

16. Hirata Y, Yamada H, Kusunose K, Iwase T, Nishio S, Hayashi S, Bando M, Amano R, Yamaguchi K, Soeki T, et al: Clinical utility of measuring epicardial adipose tissue thickness with echocardiography using a high-frequency linear probe in patients with coronary artery disease. J Am Soc Echocardiogr 28: 1240-1246.e1, 2015.
17. Nakatani Y, Kumagai K, Minami K, Nakano M, Inoue H and Oshima S: Location of epicardial adipose tissue affects the efficacy of a combined dominant frequency and complex fractionated atrial electrogram ablation of atrial fibrillation. Heart Rhythm 12: 257-265, 2015.

18. Mazurek T and Opolski G: Pericoronary adipose tissue: A novel therapeutic target in obesity-related coronary atherosclerosis. J Am Coll Nutr 34: 244-254, 2015

19. Pawar AS, Zhu X-Y, Eirin A, Tang H, Jordan KL, Woollard JR, Lerman A and Lerman LO: Adipose tissue remodeling in a novel domestic porcine model of diet-induced obesity. Obesity (Silver Spring) 23: 399-407, 2015.

20. Patel VB, Mori J, McLean BA, Basu R, Das SK, Ramprasath T, Parajuli N, Penninger JM, Grant MB, Lopaschuk GD, et al: ACE2 deficiency worsens epicardial adipose tissue inflammation and cardiac dysfunction in response to diet-induced obesity. Diabetes 65: 85-95, 2016.

21. Antonopoulos AS, Margaritis M, Verheule S, Recalde A, Sanna F, Herdman L, Psarros C, Nasrallah H, Coutinho P, Akoumianakis I, et al: Mutual regulation of epicardial adipose tissue and myocardial redox state by PPAR- $\gamma /$ adiponectin signalling. Circ Res 118: 842-855, 2016.

22. Aydın AM, Kayalı A, Poyraz AK and Aydın K: The relationship between coronary artery disease and pericoronary epicardial adipose tissue thickness. J Int Med Res 43: 17-25, 2015.

23. Chaowalit N, Somers VK, Pellikka PA, Rihal CS and Lopez-Jimenez F: Subepicardial adipose tissue and the presence and severity of coronary artery disease. Atherosclerosis 186: 354-359, 2006.

This work is licensed under a Creative Commons Attribution-NonCommercial-NoDerivatives 4.0 International (CC BY-NC-ND 4.0) License. 